\title{
Positional goods and Robert Lee Hale's legal economics
}

\author{
MASSIMILIANO VATIERO* \\ Institute of Law, University of Lugano, Lugano, Switzerland
}

\begin{abstract}
The legal realist Robert Lee Hale offered a definition of freedom as a zero-sum game: each volitional freedom implies some degree of coercion over other people's freedom, and at the same time one's freedom is subject to some degree of control and coercion by others. The objective of our work is to develop this idea along with the theory of positional goods. This allows us to illustrate the externalities deriving from the 'consumption' of freedom and detail the role of the lawmaker in accordance with the Halean contribution.
\end{abstract}

To protect certain kinds of freedom and suppress other kinds is one of the principal functions of a legal system. M. R. Cohen, 'Freedom: Its Meaning', in The Faith of a Liberal, p. 163, 1946.

\section{The issue}

Rober Lee Hale - professor of law and economics at Columbia University from 1919 through the mid-1950s - was a legal realist who drew upon the emerging tradition of institutional economics ${ }^{1}$ and a leading exponent of the first movement of Law and Economics. ${ }^{2}$ In particular, Hale focused on one of the fundamental themes of the American critical legal tradition: the theory

\footnotetext{
*Email: vatierom@usi.ch
}

The author wishes to thank Luca Fiorito, Ugo Pagano, and the anonymous referees of this journal for their comments and suggestions. In addition, the author is grateful for the hospitality of the Institute of Law and Economics, University of Hamburg, Germany.

1 The title of this article refers to 'legal economics'. However, as noted by one referee, to say that Hale's discussion of freedom is legal may be misleading because Hale uses a theoretical framework to illuminate questions that are legally but also politically and morally relevant. Hence, it is worth underlining that our meaning of 'legal' may be intended along with an Old Institutional Economics perspective, whose Hale's though is an important part. Accordingly, Mercuro et al. (2006) speak about Hale as a legal economist.

2 His ideas were very influential among scholars at Columbia University (e.g. John Maurice Clark and James C. Bonbright) and among American academic lawyers and economists. For biographical information, see Samuels (1973), Duxbury (1990), Fried (1998), Mercuro et al. (2006), and Fiorito and Vatiero (2011). 
of freedom as a concealed coercion - coercion in the Halean perspective stands for restriction on others. The main thesis of this work is that Hale's definition of freedom as mutual coercion (i.e. that exercising one's own freedom necessarily entails limiting someone else's freedom) overlaps with the zero-sum characterization of so-called positional goods, that is, those goods for which the positive consumption by one agent is necessarily related to the negative consumption of the same good by another agent.

For our purpose, we have to furnish, first of all, a brief explanation of the concept of positional goods. Although Karl Marx (1978) had already noted that agents' wants, demands and pleasures are largely influenced by society, Thorstein Veblen (1899) had already emphasized the importance of one's relative position in society with reference to the concept of conspicuous leisure and consumption, and Alfred Marshall, in his Principles of Economics, had already recognized 'the power and prevalence of the human desire for distinction' (1961: 12), it was Fred Hirsch (1976) who coined the concept of 'positional goods' in his Social Limits to Growth. The expression social limits means that these goods arise from the relative standings of different individuals - if you go up, I come downand not from physical or natural limitations. For instance, the land in Montioni Park is physically (or naturally) scarce, unlike positional goods such as power (Vatiero, 2009), status, prestige, honors and 'the rarest distinctions are few [that is, scarce]', not as a result of 'either the niggardliness of nature or the burden of the labor' (i.e. physical limits or scarcity), but rather 'they are scarce for the obvious reason that there is no standing room at the top of the pyramid [...] They would not be what they are if they were attainable to many' (Polanyi, 1968: 94). According to Pagano (1999, 2007), the consumption of positional goods is a zero-sum game: a positive level of their consumption by one party implies that at least one other party's level of consumption must be negative. Hence, in the context of two agents, a pure positional good is a good whose positive consumption for one agent is related to the equal negative consumption for another agent.

In a similar fashion, Hale represents the economy as a structure of zerosum positions - what one party gains, the other loses. The idea of economic freedom in Hale's thought relies on the idea that each person exerts some degree of coercion over other people's liberty - while at the same time his or her own liberty is subject to some degree of control and coercion by others. That is, each freedom implies at least one 'coercer' and at least one 'coercee', or better, at least one party consuming a positive level of freedom - the coercer and at least one other party consuming a corresponding negative level of freedom - the coercee. Hence, the coercer can consume freedom only if a coercee exists, and both parties cannot consume the same level of freedom because the total consumption of Halean freedom (as well as the total consumption of each positional good) is by definition null (cf. also Fried, 1998: 51-54; and Ayres, 1999a). 
In more detail, following the contributions of Wesley Hohfeld, ${ }^{3}$ Hale takes into account both the adversarial and relational nature of jural relationships: ${ }^{4}$ a legal claim by one party is related to a duty by another party, one power is related to one liability (in the terminology of Hohfeld). Analogously, an increase of freedom for one party (the coercer) is related to a decrease of freedom for another party (the coercee). According to Hale et al. (1923: 54), it is always a question of 'liberty against liberty'. Moreover, as suggested by the title of one of Hale's most important works, Freedom through law 1952, the freedom of one party can be increased by restrictions provided through the law on the freedom of others (cf. also Fuller, 1954). This also means that through legislation, a lawmaker can regulate and manage the 'positional' relationship between the coercer and the coercee, and affect the allocation of freedoms among them.

The novelty of this work lies in the linking of a legal concept, i.e., the Halean idea of freedom, and a theoretical economic notion, i.e., the positional good. This sheds light on the actual meaning of freedom in the market and in contracts, enables the employment of economic tools in the analysis of efficiency ${ }^{5}$ in creating or delimiting freedoms, and explains the significance of the coercion of the State in regulating individual interactions.

The next section offers a characterization of freedom consistent with the original contributions of Robert Lee Hale. Section 3 introduces a textbooklike framework in which freedom is explained as a positional good. Section 4 discusses the set of 'microeconomic' optimality conditions using the Halean notion of freedom. Accordingly, Section 5 is dedicated to illustrating the role of the State and statesmen. Section 6 reviews our main findings.

\section{Halean freedom and coercion}

Hale does not furnish an exact and clear-cut definition of freedom. He seems to be interested, instead, in stressing that freedom (whatever it means) is scarce and can be allocated by legal and institutional arrangements furnished by the lawmaker.

3 Indeed, Hale was clearly influenced by the thrust of Wesley Newcomb Hohfeld's paradigm of jural common denominators and its (correlating) fundamental conceptions; see Hale (1922: 212; 1927: 523). Hohfeld's framework is, nonetheless, largely adopted ad hoc to explicate certain arguments rather than as a comprehensive analytical tool (cf. Fiorito and Vatiero, 2011; Samuels, 1973).

4 A jural relation is defined as a situation of a legal and material fact through which one by his or her will may restrict or claim to restrict, presently or contingently, with the aid of the law, the freedom of action of another (cf. Vatiero, 2010).

5 Even if our illustration of the concept of freedom is based on a welfarist framework, further relevant issues may come from a non-welfarist approach such as one recalling Amartya Sen's discussion of the impossibility of Paretian liberal and resting on subsequent literature on social choice theory (see, among others, Anand et al., 2009). 
In accordance with Samuels (1973) and Mercuro et al. (2006), Hale drew a fundamental distinction between voluntary and volitional freedom. Voluntary freedom is a hypothetical case in which agents are faced merely with the scarcity of resources in nature; a freedom is volitional when each choice also depends on others' choices. In other words, a voluntary freedom refers to behaviors and choices that are autonomous and unconstrained by others, while a volitional freedom means that behaviors and choices are limited by society (i.e. social limits), that is, by other individuals' behaviors and choices. ${ }^{6}$ In this respect, coercion represents the impact of the behaviors and choices of others in limiting one's freedom, i.e., reducing one's voluntary freedom to volitional freedom.

Given that volitional freedom is 'socially' scarce, the State by law can redistribute freedoms between agents: it can permit certain freedoms for one agent and exclude by coercion the counterparty from consuming certain liberties. For instance, in each market exchange one party's consent to a transaction is extracted or obtained from the other through the market price, which the law regards as legitimate. In this respect, 'every price, like every tax, is in some measure regulatory and to some extent interposes an economic impediment to the use of the article for which the price is charged' (Hale, 1939: 566).

Let us consider the early and pivotal case Alaska Packers' Assn. v. Domenico (117 F.99, 9th Cir. 1902): the defendant hired sailors in San Francisco for a voyage to Alaska to fish for salmon, but when the boat arrived in Alaskan waters, the seamen declared they would not work unless the defendant agreed on a $66 \%$ increase in wages. The defendant who had to accept the seamen's requests was 'coerced' by the threat of strike in a circumstance that offered few alternatives in the remote waters. Given that the defendant could not replace them for the short Alaskan fishing season, he agreed to pay the sailors the higher wages they demanded when the boat returned to San Francisco. Instead, once the boat returned to San Francisco, the defendant reneged and the seamen sued. The Court held that the increase in the wages of the sailors who threatened to strike at short notice in remote waters was unenforceable because the choice was made under coercion.

Nevertheless, in accordance with Halean thought, coercion in an economy is the result of ineradicable social limits involving each interaction among individuals. While the outcome of an independent fisher derives from his or her choices, with the only constraints deriving from naturally scarce goods such as the time (that is, it is a voluntary freedom in Hale's terminology), in the case of a fisher working together with other fishers or hiring them as in Domenico,

6 As affirmed at the beginning of this section, Hale did not offer a clear definition of freedom; however, Halean freedom is related to scarcity referring to outside options and potential choices available to agents. That is, Halean freedom seems to stand for freedom of choice. For an illuminating review of the meaning of freedom of choice, see Dowding and van Hees (2009). 
the freedom to organize the activity is also constrained by social factors like the choice of others (that is, it is a volitional freedom). In this respect, every choice is made under coercion, both in the remote waters of Alaska and in the harmless harbor of San Francisco.

Moreover, the lawmaker can furnish more freedoms to the employer at the cost of reducing the freedoms of the fishers. That is, the State, with the aid of the law, can redistribute freedoms, but the sum of the freedoms of the parties must be null: in Domenico, the decision of the Court - the agreement to increase the wages of the sailors was considered unenforceable because it was obtained in the remote waters of Alaska - determines an increase in the freedom of the employer and a decrease of the freedom of the fishers. The lawmaker or the enforcer, by setting or deciding upon one legal arrangement rather than another, allocates freedoms among agents.

More generally, every market transaction, Hale would conclude, almost invariably involves volitional freedom: one coerces the other through his or her choices. Each economy connotes, therefore, regulation and constraining governance; the actual freedom 'is typically volitional and not voluntary' (Mercuro et al., 2006: 536). Indeed, each freedom is related to an ineradicable degree of compulsion, duress and coercion because what one party gains, the other loses (cf. Hale, 1935a, 1935b, 1943; cf. also Samuels, 1984). In particular, 'Hale [...] chooses to see coercion where others would see freedom' (Duxbury, 1990: 436). Coercion is an inevitable part of each economic interaction and it is only a term that represents all socio-economic relationships. For this reason, Hale does not intend the term 'coercion' to bear a negative connotation: 'Coercion is not a ground for condemnation [...] hence, it seems better, in using the word "coercion", to use it in a sense which involves no moral judgment' (Hale, 1923: 476).

\section{An analytical illustration}

A further illustration can come from Defoe's story of Robinson Crusoe. Before the arrival of man Friday, Robinson Crusoe consumes voluntary freedom: he spends his resources (e.g. time) in facing natural limits. When Friday arrives, social limits emerge and Robinson starts to consume positional goods like power and volitional freedom, given that each of his choices also depends on man Friday's choices, and vice versa. In analytical terms, let us indicate with $R$ the agent Robinson and with $F$ the agent Friday; and with $x, y$ and $z$ three kinds of goods - respectively, private (e.g. liquor recovered from the boat), public (e.g. the air of the island) and positional (in our case, we will consider Halean freedom) ones. We indicate with a capital letter the total consumption of every kind of goods. Hence, $X$ is the sum of two individual consumptions of liquor: $x_{R}+x_{F}$. Note that both parties may consume positive (but limited) levels of liquor. Let us consider the case of the air. There are no physical limits, i.e. no rivalry on the 
Figure 1. Consumption of public, private and positional goods.

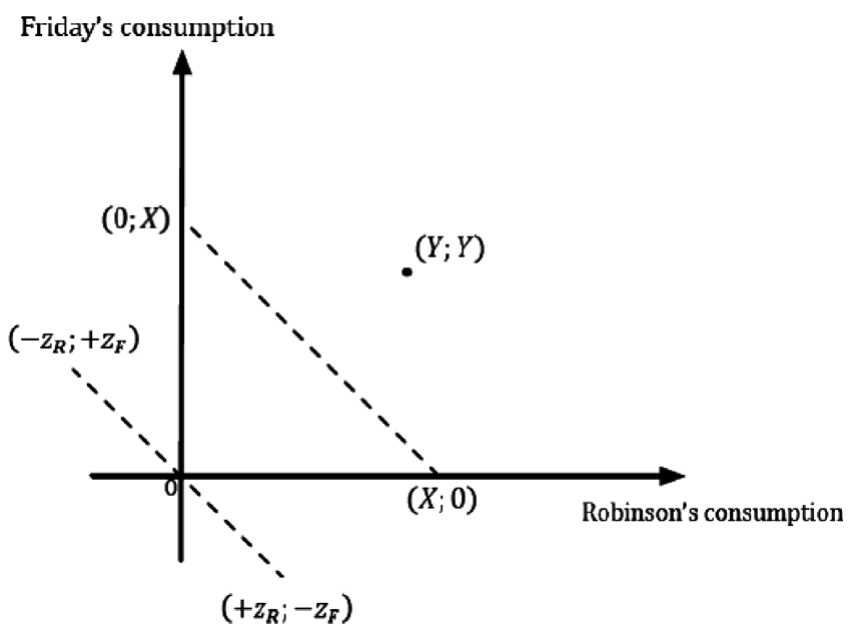

consumption; therefore every agent can consume the total level $Y$ :

$$
y_{R}=x_{F}=Y \text {. }
$$

Finally, consider volitional freedom: a positive level for Robinson, $z_{R}$, implies an equivalent negative level for Friday, $z_{F}$. Therefore, the Halean volitional freedom can be represented as

$$
z_{R}+z_{F}=0
$$

In a Cartesian plane with consumption for Robinson on the abscissa and consumption for Friday on the ordinates as in Figure 1, we can illustrate the characteristics of the consumption of these three kinds of goods.

In the case of private goods, given a certain total amount, other individuals consume a zero amount of what each individual chooses to consume. Hence, the consumption of private goods is represented by the segment $(X ; 0)(0 ; X)$ in Figure 1. For a pure public good, instead, each agent consumes the same positive amount as the other agent consumes. This is illustrated by the point $(Y ; Y)$. Finally, volitional freedom is limited by the social scarcity, which leads to a zerosum game, as illustrated by the line $\left(-z_{R} ;+z_{F}\right)\left(+z_{R} ;-z_{F}\right)$ for which the total amount of consumption of voluntary freedom is null. As with positional goods 'what each of us can achieve, all cannot' (Hirsch, 1976: 5), all cannot consume the volitional freedom, by definition.

In this respect, there is a character of public-ness in the consumption of positional goods such as Halean freedoms, albeit with the opposite sign to a public good. For both public and positional goods, consumption by an individual implies a certain level of consumption for others. If one individual consumes more of a public good, the other agent will consume more of this good (cf. equation 
(1)); on the contrary, if one individual consumes more of a positional good (e.g. Halean volitional freedom), the other agent will consume a greater negative amount of this positional good (cf. equation (2)). Public and positional goods imply 'external economies' derived from an intrinsic 'jointness demand', 7 leading to a rule of vertical summation/subtraction of individual marginal valuations, as illustrated in the next section.

\section{Welfare, efficiency, and freedom}

Although Hale and Old Institutionalism rejected the neoclassical emphasis on the Pareto efficiency, they nonetheless considered efficiency an important variable in legal-economic analysis. In our microeconomy characterized by three kinds of goods (private, public, and positional goods) and two agents (Robinson and Friday), freedom is included in the utility function $f(\cdot)$ (twice differentiable) just like other economic goods. The utility functions for our two agents are $f_{R}\left(x_{R}, Y, \pm z\right)$ and $f_{F}\left(X-x_{R}, Y, \mp z\right)$.

Assume a private good as numeraire, for instance a certain quantity, say, a sip, of liquor. Moreover, for the sake of simplicity, consider one kind of freedom, the freedom of dress. In particular, let us assume (as illustrated by Defoe) that Robison is annoyed because Friday walks naked. The marginal valuations of substitution indicated with $v_{i}(z)$ stand for how many sips of liquor Robinson is willing to give up and Friday is willing to accept in order to, respectively, 'acquire' and 'sell' Friday's freedom to walking naked. Hence, the marginal social value of unit $z$ of freedom is given by

$$
v_{R}(+z)+v_{F}(-z) .
$$

Note that although the sum of the consumption of freedom is zero (cf. equation (2)), the impact of freedom on social welfare (as a function of individual utilities measured in sips of liquor) may be positive, zero, or negative. Indeed, the outcome of equation (3) depends on agents' preferences in the consumption of freedom. The marginal utility for one party deriving from a positive consumption of freedom can be higher than, equal to, or lower than the marginal (dis-)utility deriving from a negative consumption of freedom. Given that it is not clear what impact on welfare will result from the consumption of freedom, in accordance with Hale, coercion related to freedom cannot be condemned a priori.

Finally, let us denote by $c_{z}$ the marginal cost of freedom in terms of the numeraire. Indeed freedom is costly; for instance, it calls for the 'production' of specific conditions. On Robinson's island, it means, for instance, the production of new clothes for Friday. In the modern economy, it signifies, instead, the 'production' of structures for enforcing freedoms (e.g. courts, patrols, and so

7 The meaning of jointness demand in the case of a public good is introduced and detailed in Samuelson (1954). 
on). Therefore, the first-order condition for the 'socially' optimal quantity of freedom can be written as ${ }^{8}$

$$
v_{R}(z)-\left\|v_{F}(-Z)\right\|=c_{z} .
$$

Hence, in equation (4) the difference among individual marginal valuations is set equal to the marginal cost.

Condition (4) is different from the standard optimality condition for private goods, where all marginal valuations of substitution between private goods are equal to the respective marginal costs. That is, from a diagrammatic view, for positional goods such as Halean freedom, individual demand should be derived vertically and not horizontally, as in the case of private goods. Moreover, note also that condition (4) is the opposite of the Samuelsonian formula for public goods (cf. footnote 8): the rule for deriving total demand is not the vertical summation of individual demands, as in public goods, but rather their vertical subtraction.

Let us place the relative price (the price of freedom in terms of sips of liquor) on the $Y$-axis and Robinson's volitional freedom on the $X$-axis, as in Figure 2; in order to take into account externalities, Robinson should not only pay a price for the production cost of freedom, $c_{z}$, but also a price for the relatively 'dangerous' effect on Friday $\left\|v_{F}(-z)\right\|$. Hence, the price should be a sort of a 'double price': 9 in our case, it is determined by the price of new clothes of Friday plus the price for remunerating Friday for selling his freedom to walking naked.

Note that in the case of a private good, the price is given only by marginal cost and the individual marginal valuation of a potential buyer. Instead, the double price in the case of positional goods, in general, and volitional freedom, in particular, may bring about market failures and can justify the active role of the State and statesmen, as we describe in the next section.

\section{The role of the statesmen}

Hale (1923) begins his celebrated essay on 'Coercion and Distribution in a Supposedly Non-Coercive State' by asserting that for libertarians:

The practical function of economic theory is merely to prove to statesmen the wisdom of leaving such matters alone, not to aid them in the process of interfering [...] But a careful scrutiny will, it is thought, reveal a fallacy in this view, and will demonstrate that the systems advocated by professed upholders of laissez-faire are in reality permeated with coercive restrictions of individual freedom [...] Some sort of coercive restriction of individuals, it is believed, is absolutely unavoidable (470)

8 It is useful to compare the reformulation of equation (4) with the standard Samuelsonian formula for public goods: in our case, $v_{R}(Y)+v_{F}(Y)=c_{Y}$.

9 Double price is related to the fact that positional goods are 'double' rival and 'double' excludable in the consumption (cf. Vatiero, 2009). 
Figure 2. Vertical subtraction rule.

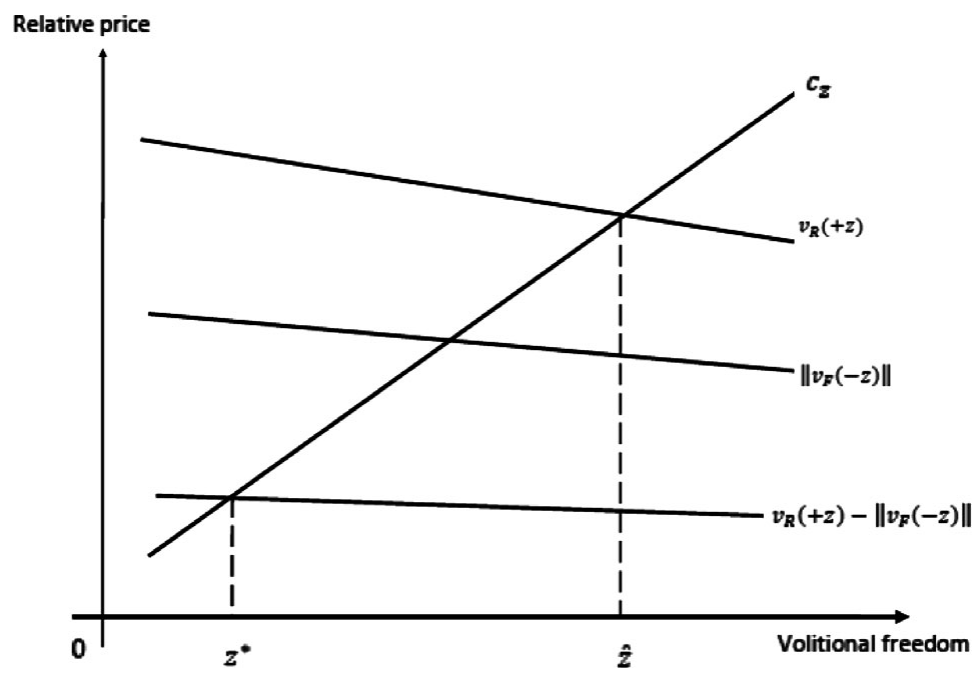

Hence, given that every economic context entails coercion, the State may stimulate by law an efficient (or more efficient) allocation of freedoms. On the island inhabited by Robinson and Friday, the social welfare deriving from freedom of dress is the result of the surplus for Robinson, i.e. $v_{R}(+z)-c_{z}$, and the negative externality for Friday, as identified by $-\left\|v_{F}(-z)\right\|$. Neglecting the negative externality would create an overabundance $\hat{z}$ of Robinson's volitional freedom, as illustrated in Figure 2. Hence, the lawmaker should interfere and set legal remedies (which likely would be contested by libertarians) in order to compensate Friday and 'maneuver' the relationship toward the achievement of an efficient level of freedom, i.e. $z^{*}$.

In this respect, the problem of the consumption of freedoms is the same problem as that of the consumption of positional goods, and it closely resembles a Lindahl equilibrium: ${ }^{10}$

[t]he existence, enforcement or, even, the definition of property rights is as hard in the case of positional goods as it is for the case of public goods. However, the consequences of the failure to establish property rights have opposite signs. In the case of public [...] goods, the consequence of this failure implies that an agent consuming the public good does not get paid for other people's consumption; in the case of a positional [...] good, the equivalent

10 However, as noted by an anonymous referee, public goods rest on positive externalities, while positional goods involve both positive and negative externalities. This distinction may be very relevant if in a public choice perspective we consider a State with a democratic regime, because in the case of a positional good, one party (Robinson-like) will surely vote against an intervention of the State to compensate Friday (who suffers a negative externality), while in the case of a public good, such a party could vote in favor of an intervention of the State to supply the good. 
failure implies that an agent consuming positive amounts is not charged for the negative consumption of other agent's consumption. (Pagano, 1999: 71)

Therefore, statesmen interested in maximizing social welfare should interfere with economic matters in order to (try to) govern and regulate by law market failures deriving from the externalities involved in the consumption of freedom. Externalities, indeed, may emerge from positional concerns, in turn justifying the legislative intervention of a lawmaker to safeguard agents who consume a negative level of freedoms, or to redistribute them. However, this does not mean that positional concerns disappear, but rather that they are 'regulated'. Hale's sophisticated notions of coercion and volitional freedom can be seen, therefore, as attempts to amend the bilateral characterization of market exchange between private parties and to include the important role played by the lawmaker in shaping and ordering legal and economic processes.

As a result, Hale discredited the libertarian notion of liberty - today, we could say, such a liberty refers to Berlin's (1969) negative liberty ${ }^{11}$ - and its reliance on laissez-faire markets (Ayres, 1999b). However, State intervention is not justified by Hale through the argument posed by Berlin's (1969) positive liberty. ${ }^{12}$ His argument instead is based on the idea that the State may be central in the regulation of freedoms and its intervention could 'correctly' allocate them in accordance with some criterion; for instance, a criterion of Pareto efficiency.

\section{Concluding remarks}

For Hale, as for other institutional economists such as Thorstein Veblen and John R. Commons, the idea of an economy based upon freedom is effectively a contradiction because of the fact that a positive level of freedom for one party must entail a negative level of freedom for another party. That is, each freedom is constrained in a zero-sum consumption game, and coercion represents such a constraint. For this reason, Hale intends coercion in a neutral sense and does not condemn it a priori; he simply recognizes its existence and underlines its basic forms of existence in economic life. That is, Hale argued that the economy is a system of mutual coercion, understood to comprise the impact of the behaviors

11 The concept of negative liberty refers to an individual's liberty from being subjected to the action, in particular, of the State. In this negative sense, one is considered free to the extent to which nobody interferes with one's activity. On the contrary, the positive meaning stands for the liberty of acting in such a way as to take control of one's life and realize one's fundamental purposes, namely, achieving a sort of self-mastery: 'The positive sense of the word "liberty" derives from the wish on the part of the individual to be his own master [...] I wish to be a subject, not an object' (Berlin, 1969: 129). According to Berlin (1969), this distinction is deeply embedded in the political tradition: the notion of negative liberty being associated most strongly with the classical British political philosophers (e.g. J. Locke, T. Hobbes, A. Smith, J. Bentham, and J. S. Mill), and positive liberty with continental European thinkers such as G. W. F. Hegel, J. J. Rousseau, J. W. von Goethe, I. Kant, and K. Marx.

12 See supra note 11 . 
and choices of others. Such coercion limits one's freedom, shifting it from the purely voluntary to the purely volitional.

Apropos of voluntary freedom, we offered a re-assessment of this idea along with the notion of the positional good. This allows us to underline the social scarcity and zero-sum game conditions of Halean freedom. Moreover, we have illustrated economic concerns that may not permit the achievement of Pareto optimality in the case of the consumption of freedom. Accordingly, the lawmaker interested in efficiency may interfere and intervene in the economy in order to regulate and manage externalities deriving from positional concerns involved in the consumption of Halean freedom.

As a result, in accordance with Hale, the government redistributes - rather than necessarily curtailing - liberties when it intervenes. The State by law permits certain freedoms for some agents but excludes by coercion other agents from consuming certain liberties. These State interventions are seen by some economic agents as freedom and by some as coercion, with different perceptions among economic agents. Moreover, even market exchange in the economy is a legal structure of mutually coercive arrangements and relationships. The price states the conditions that permit the consumption of a volitional freedom for one agent, while restricting such consumption for another agent. Hence, whereas the 'libertarians' tend to see only the State as the repository of coercion, institutionalists, and certainly Hale, see both the market and the State as coercive. For this reason, even if Hale did not undermine the virtues of free markets, he rejected a priori the argument that the free market was necessarily better than redistributive regulation by the State.

\section{References}

Anand, P., P. K. Pattanaik and C. Puppe (eds.) (2009), The Handbook of Rational and Social Choice: an Overview of New Foundations and Applications, Oxford: Oxford University Press.

Ayres, I. (1999a), 'Taking Issue with Issue Advocacy', Virginia Law Review, 85(8): 17931802.

Ayres, I. (1999b), 'Discrediting the Free Market', The University of Chicago Law Review, 66(1): 273-296.

Berlin, I. (1969), 'Two Concepts of Liberty', in I. Berlin (ed.), Four Essays on Liberty, London: Oxford University Press, pp. 118-172.

Dowding, K. and M. van Hees (2009), 'Freedom of Choice', in P. Anand, P. K. Pattanaik and C. Puppe (eds.), The Handbook of Rational and Social Choice: An Overview of New Foundations and Applications, Oxford: Oxford University Press, pp. 374392.

Duxbury, N. (1990), 'Robert Hale and the Economy of Legal Force', The Modern Law Review, 53(4): 421-444.

Fiorito, L. and M. Vatiero (2011), 'Beyond Legal Relations: Wesley Newcomb Hohfeld's Influence on American Institutionalism', Journal of Economic Issues, 45(1): 199222. 
Fried, B. (1998), The Progressive Assault on the Laissez Faire: Robert Hale and the First Law and Economics Movement, Cambridge: Harvard University Press.

Fuller, L. L. (1954), 'Some Reflection on Legal and Economic Freedoms - A Review of Robert L. Hale's Freedom Through Law', Columbia Law Review, 54(1): 70-82.

Hale, R. L. (1922), 'Rate Making and the Revision of the Property Concept', Columbia Law Review, 22(3): 209-216.

Hale, R. L. (1923), 'Coercion and Distribution in a Supposedly Non-Coercive State', Political Science Quarterly, 38(3): 470-494.

Hale, R. L. (1927), 'Value and Vested Rights', Columbia Law Review, 27(5): 523-529.

Hale, R. L. (1935a), 'Force and State: A Comparison of "Political" and "Economic" Compulsion', Columbia Law Review, 35(2): 149-201.

Hale, R. L. (1935b), 'Unconstitutional Conditions and Constitutional Rights', Columbia Law Review, 35(3): 321-359.

Hale, R. L. (1939), ‘Our Equivocal Constitutional Guaranties', Columbia Law Review, 39(4): 563-594.

Hale, R. L. (1943), 'Bargaining, Duress, and Economic Liberty', Columbia Law Review, 43(5): 603-628.

Hale, R. L. (1952), Freedom Through Law: Public Control of Private Governing Power, New York: Columbia University Press.

Hale, R. L., J. H. Hollander and S. A. Lewisohn (1923), 'Discussion of the Restatement and Clarification of the Law', Proceeding of the Academy of Political Science in the City of New York, 10(3): 47-58.

Hirsch, F. (1976), The Social Limits to Growth, Cambridge: Harvard University Press.

Marshall, A. (1961), Principles of Economics, London: Macmillan.

Marx, K. ([1891] 1978), 'Wage Labour and Capital', in R. C. Tucker (ed.), The Marx-Engels Reader, 2nd edn, New York: W.W. Norton \& Company, pp. 203-217.

Mercuro, N., S. G. Medema and W. J. Samuels (2006), 'Robert Lee Hale (1884-1969) - Legal Economist', in J. G. Backhaus (ed.), The Elgar Companion to Law and Economics, Cheltenham: Edward Elgar, pp. 531-544.

Pagano, U. (1999), 'Is Power an Economic Good? Notes on Social Scarcity and the Economics of Positional Goods', in S. Bowles, M. Franzini and U. Pagano (eds.), The Politics and the Economics of Power, London: Routledge, pp. 63-84.

Pagano, U. (2007), 'Positional Goods and Asymmetric Development', in P. Yotopolus and D. Romano (eds.), Asymmetries in Globalization, London: Routledge, pp. 28-47.

Polanyi, K. (1968), Primitive, Archaic and Modern Economies: Essays of Karl Polanyi, New York: Doubleday/Anchor Books.

Samuels, W. J. (1973), 'The Economy as a System of Power and Its Legal Bases: The Legal Economics of Robert Lee Hale', University of Miami Law Review, 27(3-4): 261-371.

Samuels, W. J. (1984), 'On the Nature and Existence of Economic Coercion: The Correspondence of Robert Lee Hale and Thomas Nixon Carver', Journal of Economic Issues, 18(4): 1027-1048.

Samuelson, P. A. (1954), 'The Pure Theory of Public Expenditure', Review of Economics and Statistics, 36(4): 387-389.

Vatiero, M. (2009), Understanding Power. A 'Law and Economics' Approach, Saarbrücken: VDM-Verlag Publisher.

Vatiero, M. (2010), 'From W. N. Hohfeld to J. R. Commons, and Beyond? A "Law and Economics" Enquiry on Jural Relations', American Journal of Economics and Sociology, 69(2): 840-866.

Veblen, T. (1899), The Theory of the Leisure Class, New York: MacMillan. 